\title{
Insubordinação Criativa: um convite à reinvenção do educador matemático
}

\section{Creative Insubordination: an invitation to reinvent the mathematics educator}

\author{
Beatriz Silva D'Ambrosio* \\ Celi Espasandin Lopes ${ }^{* *}$
}

\begin{abstract}
Resumo
Neste artigo apresenta-se o conceito de insubordinação criativa com o objetivo de analisar as contribuições que atitudes decorrentes dessa perspectiva podem trazer aos fazeres dos educadores matemáticos. Para isso, colocam-se em pauta discussões a respeito da complexidade educativa, da autonomia profissional, da prática reflexiva e do trabalho colaborativo. Pretende-se suscitar reflexões sobre a questão: Por que considerar a insubordinação criativa para redimensionar as práticas dos educadores matemáticos? Diante desta intenção, busca-se dialogar com teóricos da Educação e da Educação Matemática que se expressam de forma crítica e comprometida com a democracia, a justiça social, a ética e a solidariedade. Assim, justifica-se a necessidade de a comunidade reinventar as práticas da Educação Matemática.
\end{abstract}

Palavras-chave: Insubordinação. Criatividade. Professor. Pesquisador. Educação Matemática.

\begin{abstract}
In this article we introduce the concept of creative insubordination with the goal of analyzing the contributions that this perspective can make in transforming the practices of mathematics educators. The discussion is grounded in considerations of the complexities of education, professional autonomy, reflective practice, and professional collaborations. Our intention is to incite reflections around the question of why the field should consider creative insubordination in reinterpreting the practices of mathematics educators. Critical theories of education and mathematics education, which envision democracy, social justice, ethics, and solidarity as goals of the educational process, are at the heart of our discussions. As such, we justify the need for the community to consider the reinvention of the practices of mathematics educators.
\end{abstract}

\footnotetext{
* Doutora em Educação Matemática pela Indiana University Bloomington (IUB), Bloomington, IN, USA. Professora e pesquisadora no Departamento de Matemática de Miami University (MU), Oxford OH USA. Endereço para correspondência: Department of Mathematics, Miami University, Oxford OH 45056, USA. E-mail: dambrobs@miamioh.edu.

${ }^{* *}$ Doutora em Educação pela Universidade Estadual de Campinas (UNICAMP), Campinas, SP, Brasil. Docente do Programa de Pós-Graduação em Ensino de Ciências e Matemática da Universidade Cruzeiro do Sul (SP), São Paulo, Brasil. Endereço para correspondência: Av. Gessy Lever, 915/383, Valinhos, São Paulo, Cep: 13272-000. Brasil. Email: celilopes@uol.com.br.
} 
Keywords: Insubordination. Creativity. Teacher. Researcher. Mathematics Education.

\section{Introdução}

O conceito de insubordinação criativa surgiu em 1981 quando Morris et al. publicaram um relatório sobre um estudo etnográfico realizado com 16 diretores de escolas de Chicago em que se discutiu as ações de insubordinação criativa como um recurso diante da burocracia educacional. Esse estudo revela também que os gestores acabam, por vezes, tomando decisões que não atendem às expectativas de diretrizes superiores, pois percebem a necessidade de desobedecer ordens em prol da melhoria e do bem estar da comunidade educacional de modo a preservar princípios éticos, morais e de justiça social.

Outro estudo realizado foi o de McPherson e Crowson (1993) que também tomaram o contexto das escolas de Chicago para analisar a percepção dos diretores, participantes do estudo anterior, sobre a insubordinação criativa em suas interações com as instâncias superiores.

Ao final da década de oitenta, as ideias foram utilizadas na Enfermagem, adotando-se o termo subversão responsável, para se referir às quebras de regras que profissionais dessa área assumem, ao buscar proteger e possibilitar melhores condições aos pacientes (HUTCHINSON, 1990). Outra área de pesquisa que se apropria do conceito de insubordinação criativa é a Administração Escolar, ao desenvolver estudos com foco nas práticas dos diretores de escolas (HAYNES; LICATA, 1995).

Buscamos neste artigo abordar a questão:

Por que considerar a insubordinação criativa para redimensionar as práticas dos educadores matemáticos?

Consideramos a premissa de que atrever-se a criar e ousar na ação docente decorre do desejo de promover uma aprendizagem na qual os estudantes atribuam significados ao conhecimento matemático. Diante disso, percebemos como relevante abordar aspectos relacionados à constituição do educador matemático, seja nos cursos de formação inicial e continuada de professores, seja nos programas de formação de pesquisadores, no que se refere: à complexidade da sala de aula e da pesquisa; ao processo reflexivo sobre suas práticas; à autonomia do professor e do pesquisador; ao trabalho colaborativo; e à criatividade no fazer pedagógico e investigativo. 
Buscamos elucidar, no item a seguir, a relevância de pensar sobre as ações de insubordinação criativa dos profissionais da Educação Matemática, entendendo que esses atuam desde a escola básica até a universidade.

\section{A perspectiva da insubordinação criativa na ação docente e na pesquisa}

Os pesquisadores Haynes e Licata (1995) realizaram um estudo qualiquantitativo para analisar a frequência de insubordinação criativa na prática administrativa de 34 diretores e 5 supervisores de escolas. Evidenciou-se que os diretores com mais anos de experiência profissional apresentavam maior frequência nas ações de insubordinação criativa, pois demonstravam mais coragem na tomada de decisões. Esses profissionais eram mais admirados pelos supervisores de ensino e considerados como altamente competentes, suas atitudes não eram vistas como subversivas, pois visavam resguardar o alto nível de aprendizagem dos alunos.

Essas insubordinações criativas eram geradas pelo conflito entre as políticas públicas delineadas para as escolas e a realidade escolar. Os diretores buscavam ações que visassem à melhoria da comunidade escolar e à preservação das equipes pedagógicas de suas escolas e dos princípios de suas propostas.

A insubordinação criativa é legitimada por centrar-se em práticas profissionais alicerçadas em bases éticas. A investigação de Haynes e Licata (1995) evidenciou que nenhum supervisor, independentemente de seu compromisso com uma política pública, se apressou a repreender ou a demitir um diretor que, com o objetivo de garantir a manutenção ou a melhoria do ensino e da aprendizagem em sua escola, havia tido a ética e o bom senso de adaptar ou modificar as diretrizes dessa política. Mais frequentemente, o supervisor ignorava a insubordinação do diretor ou redefinia-a como consequência positiva e antecipada da política.

Segundo Roche (1999), a insubordinação criativa tem dois propósitos: garantir que o sistema de diretrizes não influencie negativamente os professores e os alunos e evitar a possível consequência negativa do desacato explícito, quando ele ocorre.

Gutiérrez (2013) afirma que, no ensino da Matemática, as insubordinações criativas dos professores manifestam-se por meio dos seguintes atos: criar argumentações alternativas para explicar as diferenças de aproveitamento dos alunos, rompendo com a generalização normalmente presente nos discursos de análise dos resultados deles; questionar as formas como a 
Matemática é apresentada na escola; enfatizar a humanidade e a incerteza da disciplina de Matemática; posicionar os alunos como autores da Matemática; e desafiar os discursos discriminatórios sobre os alunos.

Ao pensarmos sobre as manifestações de insubordinações criativas dos pesquisadores, verificamos que elas têm se constituído pelos questionamentos feitos a: posicionamentos metodológicos rígidos; perspectiva avaliativa da produção do outro; incoerências entre práticas e relatos de pesquisas; ação política contraditória ao discurso; critérios aleatórios utilizados para avaliar a qualidade da produção científica; distribuição de verbas para produção científica; avaliação quantitativa das publicações; posição do pesquisador como intelectual (dono do saber) nos relacionamentos entre professor e aluno e pesquisador e sujeito.

As ações de subversão responsável do professor e do pesquisador, em suas atividades profissionais diárias, decorrem do desafio que lhes é apresentado em múltiplas situações para as quais não encontram respostas pré-estabelecidas. Para fazer-lhes face, têm de pôr em movimento um conhecimento profissional construído ao longo de sua carreira, que envolve elementos como origem social, política e cultural, bem como aspectos de foro pessoal e contextual. Em seu desempenho profissional, os professores e os pesquisadores precisam mobilizar não só teorias e metodologias, mas também suas concepções, seus sentimentos e seu saber-fazer.

Um profissional da Educação que busque formar estudantes éticos e solidários não deve conceber o ensino como transmissão de conceitos já elaborados e construídos, não deve limitar sua prática docente apenas aos objetivos previamente determinados, sem considerar o contexto no qual seu aluno está inserido. Dessa forma, a atuação docente dependerá de sua sensibilidade para perceber e respeitar o processo de desenvolvimento intelectual e emocional dos alunos.

Nesse mesmo sentido, podemos refletir sobre o papel do pesquisador que também busca uma produção científica ética e comprometida com a qualidade de vida humana e que, portanto, assumirá um modo de investigar em que considere o respeito aos participantes da pesquisa e/ou aos documentos utilizados na investigação; perceba as delimitações da pesquisa realizada, sabendo que ela não se constitui em uma verdade única; e tenha sensibilidade e responsabilidade na utilização do saber produzido pelo outro.

É desejável uma postura de educador flexível diante das críticas e de aprendiz diante dos repensares. Defendemos a formação de um profissional participante, ativo, crítico e responsável, disposto a colaborar com seus pares e a buscar, coletivamente, soluções para os problemas 
educacionais que emergem em seus espaços pedagógicos.

As instituições educacionais não têm conseguido acompanhar as alterações sociais e tecnológicas ocorridas mundialmente. Cabe ao professor e ao pesquisador intervir sistematicamente na reversão desse processo, ao promover interações sociais que gerem debates sobre questões sociopolíticas. Para isso, parece-nos importante que esses profissionais tenham uma compreensão sobre a complexidade educativa.

\section{Complexidade educativa}

Em razão da complexidade e da diversidade da sala de aula em qualquer nível de ensino, o professor necessita tomar decisões rapidamente em suas ações pedagógicas. Da mesma forma, o pesquisador que desenvolve estudos em Educação também precisa considerar essa complexidade educativa e tomar decisões sobre como investigar os diversos contextos.

Dessa realidade emerge a necessidade de explorar e questionar os processos educacionais e os espaços de produção de pesquisas. Cabe considerar nossas experiências e saberes profissionais, pois produzimos conhecimento não somente intelectual e socialmente, mas também de forma emotiva e moral, por meio de nossas vivências.

Incorporar tal preocupação aos programas de formação seria, no mínimo, atender aos aspectos esquecidos ou desconsiderados na tradição academicista e técnica. Para isso, talvez precisemos conhecer e pensar sobre a realidade educativa e de produção científica desde sua complexidade, tomando decisões e realizando ações que, muitas vezes, serão subversivas, mas deverão ser realizadas com criatividade e responsabilidade.

O conhecimento pedagógico e o conhecimento científico são construídos socialmente e sujeitos a valores ideológicos e éticos de quem os seleciona, organiza e transmite. Essa produção, muitas vezes, emerge de uma complexidade educativa, a qual requer que se levem em conta perplexidades e contradições reais das instituições educacionais.

Essa importante reflexão refere-se ao fato de que nós, professores e pesquisadores, em muitos momentos carecemos de autonomia e controle sobre o nosso trabalho, porque somos cerceados pela filosofia da escola e pelo estatuto da universidade, pelos programas de curso preestabelecidos, pelas propostas curriculares elaboradas por teóricos, pelas diretrizes expressas pelos gestores e pelas políticas públicas. 
Nas palavras de Morin (1999, p. 14), “a reforma necessária do pensamento é aquela que gera um pensamento do contexto e do complexo. O pensamento contextual busca sempre a relação de inseparabilidade e inter-retroações entre todo fenômeno e seu contexto e de todo contexto com o contexto planetário".

Pensar sobre o contexto e a complexidade na Educação é fundamental, particularmente no que diz respeito à profissionalização dos educadores matemáticos. Para nos auxiliar na compreensão do contexto da vida profissional dos professores, Arnaus (1999) apresenta alguns aspectos que se referem à cultura do ensino restrita à aula; à complexidade da vida da aula; às estratégias defensivas do professorado; ao contexto institucional; ao ensino como compromisso moral; aos dilemas da prática educativa; e ao ensino como prática institucional, social, histórica e política. A autora considera que os professores têm de tolerar um alto nível de ambiguidade, incerteza e complexidade para levar a cabo a condução de um grupo em um tempo determinado e com a pressão de satisfazer demandas institucionais e sociais (ARNAUS, 1999, p. 601).

Podemos considerar que muitos desses aspectos apresentados pela autora são comuns aos professores e aos pesquisadores, sendo que, na produção de pesquisas, ainda nos defrontamos com mais alguns, que se referem a: pressão para publicações constantes; dificuldades de atender a muitas condições pré-estabelecidas pelas agências de fomento; número excessivo de orientandos; excesso de atividades decorrentes da atuação na graduação, na extensão e na pós-graduação; e demandas contínuas de emissão de pareceres e produção de relatórios. Essa complexidade em nossa vida profissional tem gerado a erosão de um tempo precioso e necessário para o redirecionamento das práticas escolares e para o debate acadêmico em nossas instituições educacionais.

Durante a carreira docente, muitas vezes, o professor e o pesquisador se deparam com uma estrutura escolar ou universitária imersa em profundo controle burocrático e tecnocrático, limitante e condicionante da ação educativa e investigativa. Às vezes, convertemo-nos em pessoas que realizam aquilo que outros especialistas têm planejado e/ou determinado fora e à margem de nossos contextos. Vivemos tensões e conflitos que, constantemente, emergem no cotidiano da escola e da universidade, sem conseguir um distanciamento emotivo, analítico, reflexivo e crítico, que nos permita encontrar solução para os dilemas emergentes das práticas educacionais e investigativas.

Apesar dos espaços complexos e repletos de conflitos, professores e pesquisadores têm 
buscado a insubordinação criativa por meio de ações reflexivas, para exercer a profissão de forma digna, responsável e comprometida com a melhoria da vida humana.

\section{A importância da ação reflexiva para a subversão responsável}

Segundo Imbernón (1999), o docente deve envolver-se ativamente em um processo de reflexão crítica acerca do ensino e da aprendizagem, analisando o significado de sua ação, esta de claro caráter social e político. Para isso, o profissional precisará exercer uma prática teórica crítica, participando de processos de produção coletiva de conhecimento e das tomadas de decisões relativas ao processo educacional. Da mesma forma, como pesquisadores, seria interessante refletir sobre as contribuições de nossa produção científica para criação de uma nova ordem social, na qual predomine o respeito às diferenças, a ética e a solidariedade humana.

A reflexão que o docente e pesquisador desenvolve em torno de sua atividade profissional (antes, durante e depois da ação) permite-lhe não apenas identificar as teorias que utiliza e as que está constantemente a elaborar, mas também tomar consciência de si próprio como profissional e como pessoa, nomeadamente em relação a suas capacidades, ao saber-fazer, aos valores e aos conhecimentos.

$\mathrm{Na}$ formação de professores, consideramos o processo reflexivo sobre a prática como fundamental. De acordo com as ideias de Dewey (1989) - um pensador dos anos 1940 -, a reflexão começa quando o sujeito se surpreende por algo, quando revela desassossego e incerteza pela ocorrência de fenômenos e, posteriormente, ao orientar as concepções particulares na consecução de uma meta.

Dewey (1989) distinguiu o ato de rotina do ato reflexivo, considerando que o primeiro se deve ao impulso, à tradição e à autoridade, enquanto o segundo é um exame ativo, persistente e cuidadoso daquilo em que se acredita ou que se pratica, à luz dos fundamentos que o sustentam e das consequências a que conduz. Esta forma de pensar impulsiona a investigação, por ser um processo que envolve intuição, emoção e paixão, sem se limitar à busca de soluções lógicas e racionais para os problemas. O autor apresenta as fases do pensamento reflexivo em dois momentos: um estado de dúvida, de vacilação, de perplexidade, de dificuldade mental, no qual se origina o pensamento; e um ato de busca, de caça, de investigação, para encontrar algum material que esclareça a dúvida, que dissipe a perplexidade. A partir dessas fases, definiu três atitudes 
essenciais à ação reflexiva: a abertura de espírito, a responsabilidade e a sinceridade.

Os estudos de Schön (2000) consideram a reflexão na ação como papel central para solucionar problemas e sugerem que o profissional tenha visão crítica sobre sua compreensão inicial do fenômeno e construa nova descrição e teoria acerca dele, permitindo-lhe intervir na prática de forma mais apropriada. Nos processos educacionais, o profissional torna-se um investigador no contexto, envolvendo-se em contínua autoformação.

Ao considerar as perspectivas de Dewey e de Schön, vislumbramos o processo reflexivo como precursor da insubordinação criativa, tendo em vista que o nosso incômodo como educadores matemáticos decorre de nossa leitura crítica sobre: as diretrizes estabelecidas pelas políticas públicas; a desprofissionalização do professor; o confronto com os dilemas e as dificuldades de nossos alunos; e os contextos diferenciados e diversos de nossas salas de aula.

Assumir uma prática reflexiva para nosso fazer profissional significa voar para além do espaço da gaiola, pois, de acordo com D'Ambrosio (2013, p. 4),

os pássaros vivendo em uma gaiola alimentam-se do que encontram na gaiola, voam só no espaço da gaiola, comunicam-se numa linguagem conhecida por eles, procriam e repetem-se e só veem e sentem o que as grades permitem. Não podem saber de que cor a gaiola é pintada por fora. No mundo acadêmico, os especialistas são como pensadores engaiolados em paradigmas e metodologias rígidas, que não permitem ver além do que é considerado academicamente correto.

Essa pertinente provocação do autor nos remete a pensar que, como professores e pesquisadores em Educação Matemática, temos que buscar uma ruptura constante com o que está posto e autodesafiar-nos para superar os paradigmas previamente determinados e a busca segura em trajetórias metodológicas já percorridas. Ou seja, sair da gaiola profissional é um ato de subversão responsável.

Nossa acomodação profissional precisa ser superada por nós mesmos e deve ser motivada por nosso interesse pessoal em uma autorreflexão sobre nossas crenças, nossos conhecimentos, expectativas e previsões. Nossa percepção de sermos seres inconclusos (FREIRE, 2005) nos remete a uma tomada de consciência sobre nossas experiências e saberes, provocando-nos a buscar uma insubordinação criativa que requer criticidade relativa a percepções, pensamentos, análises e decisões.

Assim, consideramos que os educadores matemáticos devem estabelecer como meta de seus trabalhos a aprendizagem por meio da reflexão sobre suas próprias experiências, ao 
reexaminar suas ações e tomar consciência das transformações necessárias aos seus fazeres. Para assumir e exercer essa prática reflexiva, é preciso ter percepção sobre a autonomia que o profissional da Educação deve ter em suas atitudes, que poderão se constituir em uma prática subversiva responsável, pautada na criatividade e expressa no redirecionamento de suas ações educacionais. A autonomia dos educadores matemáticos pode ser viabilizada e respaldada, quando eles se inserem em grupos de trabalho colaborativo.

\section{Autonomia, criatividade e trabalho colaborativo}

Os professores e os pesquisadores reflexivos, ao decidirem sobre sua prática, adotam medidas que estão de acordo com suas próprias perspectivas e seus valores. Eles têm clareza sobre a complexidade educativa e sabem que as soluções para os conflitos didáticos, pedagógicos e os impasses nas pesquisas somente ocorrem a partir de uma atitude de análise e deliberação dos profissionais autônomos.

Muitas problemáticas e inquietações de professores e pesquisadores têm sua origem em confrontos de valores sociais e ideias políticas. A partir de tais enfrentamentos, os profissionais que desejem assumir a subversão responsável precisarão "assumir-se como ser social e histórico, como ser pensante, comunicante, transformador, criador, realizador de sonhos, capaz de ter raiva porque é capaz de amar. Assumir-se como sujeito porque é capaz de reconhecer-se como objeto" (FREIRE, 2005, p.41).

Dessa forma, consideramos que exercer a autonomia seja envolver-se em um processo contínuo de descobertas e transformações das diferenças entre a prática cotidiana e as aspirações sociais de igualdade, justiça e democracia; de compreensão dos fatores que dificultam não apenas as alterações de condições sociais e institucionais do ensino, como também nossa própria consciência.

Nas interações na comunidade escolar e universitária, a autonomia profissional do professor e do pesquisador deve ter início pela sensibilidade moral, de forma a reconhecer os próprios limites e parcialidades, para poder compreender os de outros. Esse reconhecimento não é espontâneo - precisa ser buscado de forma exigente e trabalhosa -; tampouco pode ser imposto ou dogmaticamente estabelecido, uma vez que a autonomia profissional perde seu sentido de autossuficiência, para fazer-se solidária (CONTRERAS DOMINGO, 1997). 
A autonomia é uma qualidade na relação profissional dos professores e dos pesquisadores e, portanto, deve ser exercida com compromisso político e com ética. Reconhecemos esse processo autônomo como uma necessidade educativa, e não somente como parte da competência profissional, já que a autonomia se constitui em uma construção reflexiva baseada na colaboração e no entendimento, e não na imposição (ELLIOT, 1991).

Se considerarmos que a autonomia do profissional da Educação está relacionada aos interesses da comunidade educativa na qual atua, então, há necessidade de uma contínua busca por uma aprendizagem com abertura à compreensão e à reconstrução de sua própria identidade profissional. Dessa forma, a autonomia e o trabalho colaborativo são essenciais à identidade profissional dos educadores matemáticos, pois atribuem a eles a coragem para assumir atitudes de insubordinação criativa em prol daqueles que educam e do conhecimento que produzem e promovem.

Consideramos que toda e qualquer pessoa apresenta características individuais adquiridas na vivência de uma cultura e marcadas pelas suas expressões emocionais, o que lhe permite a percepção de novos horizontes, de forma a mergulhar em um processo criativo de atividades profissionais.

A criatividade é a capacidade de construir e elaborar o novo de forma valiosa para os outros, bem como para si mesmo (POPE, 2005). Ela é um atributo humano, pois as pessoas resolvem problemas e problematizam o tempo todo, sempre com determinado grau de criatividade, em diversos aspectos da vida diária.

O mesmo ocorre no âmbito educacional, quando se deseja a formação de estudantes criativos: é necessário que professores sejam também criativos. A criatividade humana precisa ser direcionada para ações positivas e em prol do bem-estar humano, com cuidado, para não comprometer a ética e o respeito ao outro. D'Ambrosio e D'Ambrosio (2013) alertam para a importância de a criatividade possibilitar que as pessoas atinjam seu potencial máximo, sem agir de forma irresponsável nem complacente. De acordo com esses autores, deve-se buscar uma Educação Matemática que permita aos estudantes exercer uma cidadania que contribua para a paz humana e para o estabelecimento de uma ética da diversidade que vise ao respeito, à solidariedade e à cooperação com o outro.

Nós, educadores matemáticos, precisamos ousar, em nossa produção de conhecimento, de forma autônoma, a partir de nossas visões de mundo, constituídas por crenças e concepções 
adquiridas ao longo de nossas vidas, mas lembrando-nos sempre de considerar, nos processos de interações sociais dos espaços formativos, a heterogeneidade e a diversidade.

O exercício da autonomia e o processo de criatividade no cotidiano profissional do professor e do pesquisador devem tomar a colaboração como essencial ao fazer profissional. O trabalho colaborativo pode ser uma possibilidade de os educadores compartilharem ideias, valores e compreensões por meio da socialização da elaboração de seus pensamentos e de sua prática. É recomendável um processo dialético que seja crítico, em relação às problemáticas emergentes, no preparo, na execução e na pós-execução das atividades de ensino e pesquisa (LOPES, 2003).

Assumir a perspectiva colaborativa para as ações profissionais pode possibilitar aos educadores matemáticos uma produção de conhecimento mais significativa e de relevância, atrelada ao contexto educativo real. Um exemplo disso são os grupos de estudos e pesquisas que se formam a partir de uma perspectiva solidária de produção de conhecimento.

Esses grupos são constituídos por educadores que se inter-relacionam no exercício da docência e da pesquisa, ou seja, não há mais distinção entre quem é o professor da escola e quem é o professor da universidade, todos se assumem como professores pesquisadores, que possuem, reelaboram e produzem conhecimentos (AZEVEDO; PASSOS, 2012; LOPES, 2003; LOPES, 2013; NACARATO; GRANDO, 2009; PASSOS, 2010). As publicações desses grupos têm revelado, por meio de narrativas e relatos de pesquisas, uma produção intelectual que entrelaça a reflexão, a criatividade e a autonomia. E, muitas vezes, evidenciam ações subversivas responsáveis, que promovem uma formação alicerçada nos princípios freirianos que visam à constituição de seres pensantes, comunicantes, transformadores, criadores e realizadores de sonhos.

\section{A Educação Matemática gerada pela insubordinação criativa}

A Educação Matemática tem apresentado produções diversificadas, que expressam múltiplos discursos, os quais contribuem para um repensar do processo de ensino e aprendizagem que pode ser redimensionado pelos resultados de pesquisas sobre Resolução de Problemas, Modelagem Matemática, Etnomatemática, História e Filosofia da Educação Matemática, Tecnologias em Educação Matemática... No entanto, raramente as contribuições dessas 
investigações são incorporadas às ações educacionais, pois as políticas públicas e/ou as determinações das instituições de ensino cerceiam as atitudes dos profissionais que nelas atuam. Muitas das legislações e das orientações determinadas por esses órgãos privados ou governamentais reproduzem encaminhamentos decorrentes de um sistema educacional com princípios ultrapassados e que não consideraram a realidade atual, não respeitam o direito das crianças e dos jovens a uma aprendizagem que dialogue com o diferenciado contexto sociocultural e político no qual nasceram e vivem.

Skovsmose (2012) considera que, quando a Educação Matemática é trabalhada de forma adequada, ela pode empoderar as pessoas e ser base para a cidadania crítica e para a justiça social. Com essa observação, o autor indica que a Matemática poderá ser usada para o bem ou para o mal.

Se, em nossas ações profissionais, priorizarmos uma abordagem apenas técnica, com uma perspectiva que restringe a Matemática a si mesma, poderemos apenas adestrar a pessoa em habilidades de cálculo e no uso de algoritmos, negando-lhe o conhecimento matemático necessário para a leitura de mundo a que ela tem direito. Uma forma similar de adestramento e, portanto, também tecnicista, pode ocorrer em relação ao uso das metodologias de pesquisas, quando buscamos prender pesquisadores em formação às nossas redes teóricas e metodológicas, roubando-lhes o prazer de criar e as possibilidades de ousar.

Esse movimento profissional do professor e do pesquisador os leva a constantes embates com vários dilemas e conflitos em relação às suas ações profissionais, pois eles trazem, de sua formação, crenças e concepções que se confrontam com as demandas atuais dos espaços educacionais e de pesquisa. Esses profissionais vivem imersos em tensões que ora decorrem de sua formação, que teve como modelo de aprendizagem matemática o domínio de técnicas e algoritmos, a reprodução, a memorização e a formalização excessiva. E, ora, derivam de processos de formação de pesquisadores restritos a determinados referenciais teóricos e metodológicos. A superação dessas tensões requer um distanciamento emotivo, analítico e crítico.

Muitas vezes, buscamos contornar as situações problemáticas que emergem da complexidade educativa em que nos encontramos, o que, por vezes, nos torna profissionais competentes aos olhos da instituição, mesmo que estejamos, a todo o momento, evitando os "terrenos pantanosos em questões controvertidas do conhecimento ou de atividades de ensino" (ARNAUS, 1999, p. 601). 
No fazer do educador matemático, esse solo instável é fertilizado a partir de ações oriundas dos processos de formação desse profissional e de sua leitura de mundo. Ao fazer opções por uma perspectiva teórica e metodológica de valorizar mais um conteúdo do que outro, de assumir uma concepção de avaliação e/ou de optar por uma linha de pesquisa, ele expressa o valor que atribui ao conhecimento matemático produzido historicamente.

Essa tomada de decisões constante requer, muitas vezes, assumir posturas que se contrapõem ao que está posto e determinado, seja pelo cotidiano profissional, seja por diretrizes legais. Estas seriam atitudes subversivas que visam a rupturas com o preestabelecido, de forma a criar novas dinâmicas de trabalho.

Se considerarmos como um dos objetivos primordiais da Educação Matemática a preparação do futuro cidadão capaz de ser criativo para resolver os problemas da humanidade, temos que redimensionar a Matemática que trabalhamos na formação humana. A dimensão dos problemas do planeta é de tamanha grandeza que nenhum indivíduo poderá solucioná-los sozinho e isso exige um processo de colaboração criativa de toda uma geração para a criação de uma melhor condição humana e do planeta.

Diante disso, defendemos uma prática de Educação Matemática mobilizada pelas questões sociais, econômicas, políticas, éticas, históricas e culturais. Esse horizonte está atrelado à sensibilidade para perceber as distintas Matemáticas que emergem nos múltiplos contextos e requerem novas posturas e ações dos educadores matemáticos, as quais não estão predeterminadas - precisam ser criadas a partir da interação e do diálogo com seus pares.

Quando nos defrontamos com a complexidade da sala de aula e do fazer do pesquisador, emergem dilemas e conflitos. Muitas vezes, diante deles, desenvolvemos nossas próprias estratégias e tomamos decisões que dão origem a práticas pedagógicas e investigativas, as quais podem possibilitar a toda e qualquer pessoa uma apropriação mais significativa e compreensível sobre as Matemáticas utilizadas nas diferentes instâncias da vida humana. Essa ação seria, então, caracterizada como um ato de insubordinação criativa, pois os educadores matemáticos assumiriam a imprevisibilidade presente no processo de construção de conhecimento e se dedicariam a ouvir o seu aluno, o seu sujeito, os seus colegas, ao invés de dar ouvido às diretrizes pré-estabelecidas pelas instituições.

Acreditamos que a construção resultante da reflexão e da tomada de decisão sobre suas ações profissionais possa levar os educadores matemáticos a assumir atos de subversão 
responsável, necessários para criar novas práticas em Educação Matemática, já que esta "tem sido irresponsável atendendo exclusivamente ao objetivo de melhorar o desempenho de alunos em testes padronizados ao invés de envolvê-los em reflexões necessárias para realizar o objetivo maior da Educação que é o preparo humano para participar na criação de um mundo melhor" (D’AMBROSIO; D'AMBROSIO, 2013, p. 10).

Diante dessa consideração, cabe analisar nossas ações profissionais e avaliar se não temos privilegiado responder positivamente às políticas públicas e institucionais, sem perceber que podemos, colaborativamente, superar a crença nessa formação que prioriza o domínio do conteúdo matemático, em detrimento de uma formação mais global e plena, que possibilite a constituição de uma identidade profissional pautada em princípios éticos e solidários.

\section{Considerações finais}

Neste artigo compartilhamos com os colegas nossas preocupações em relação à produção do conhecimento matemático que tem se dado nas escolas e nas universidades. Buscamos discutir o conceito de insubordinação criativa como uma possibilidade de nos articularmos em nossos espaços de trabalho de modo a resgatar nossas intenções e nossos compromissos com a Educação Matemática.

Ao ministrarmos aulas e produzirmos pesquisas nesta área de conhecimento, temos como objetivo a compreensão e o acesso de todas as pessoas a um conhecimento matemático que foi e é construído socialmente e historicamente. Isso nos remete a refletir sobre a perspectiva freireana de que não podemos

estar no mundo sem fazer história, sem por ela ser feito, sem fazer cultura, sem 'tratar' sua própria presença no mundo, sem sonhar, sem cantar, sem musicar, sem pintar, sem cuidar da terra, das águas, sem usar as mãos, sem esculpir, sem filosofar, sem pontos de vista sobre o mundo, sem fazer ciência, ou teologia, sem assombro em face do mistério, sem aprender, sem ensinar, sem idéias de formação, sem politizar... (FREIRE, 2005, p. 58).

Essa compreensão da história como possibilidade e não como determinismo seria ininteligível sem o sonho. Precisamos estar abertos ao "inédito viável" (FREIRE, 2005).

Dessa forma, cabe-nos assumir uma concepção de Educação que vise formar para a autonomia, capacitando os educandos a problematizarem o presente com vistas à construção de 
um futuro, tomando a História como possibilidade, e não como determinação. Freire (2005) nos alerta que o mundo não apenas é, ele está sendo e o papel dos homens no mundo é de quem constata e intervém.

Diante disso, convidamos os colegas a se reinventarem, como educadores matemáticos, pela perspectiva da insubordinação criativa, a qual decorre do compromisso que assumimos diante de nossas atividades diárias. Para tanto, é essencial utilizar nossos saberes de forma a proteger a integridade de nossos estudantes e de nossos espaços formativos, neutralizando os efeitos desumanizadores da autoridade burocrática. Não podemos nos imobilizar perante as ações cotidianas de nossas atividades profissionais, pois corremos o risco de cair em desesperança.

Assim, devemos investir em um processo de colaboração entre os educadores matemáticos que atuam nas escolas e nas universidades, para termos segurança para assumir atitudes e ações subversivas responsáveis. Isso deve ocorrer em prol de viabilizar uma formação matemática que permita a todas as pessoas ampliar suas visões sobre o mundo em que vivem e sentir-se aptos a transformá-lo com vistas à justiça social e à solidariedade.

Retomamos as palavras de Ubiratan D'Ambrosio, que sempre provoca nossa comunidade de educadores matemáticos a ousar em seus fazeres pela Educação, "sair da gaiola, como sair das torres de marfim, não é fácil. As gaiolas oferecem vários benefícios (abrigo, alimentação, convívio), mas o preço por estes benefícios é alto: as grades impedem sair e voltar livremente". Para este educador, nós devemos "sair, voar, conhecer a realidade ampla e identificar problemas maiores, ver e ouvir de todas as fontes e voltar livremente" (D'AMBROSIO, 2013).

Essas ideias provocativas de D'Ambrosio convergem para a perspectiva de Freire (2005) de que é uma contradição um ser consciente de seu inacabamento não buscar o futuro com esperança, não sonhar com a transformação, enfim, não buscar a construção de um mundo onde todos possam realizar-se com autonomia.

Se cabe à Educação problematizar o futuro para que o sonho de um mundo melhor não se perca, cabe aos educadores matemáticos problematizar suas atividades profissionais. Precisamos ter consciência do nosso condicionamento e a clareza de que não somos determinados - há possibilidade da transformação. 


\section{Referências}

ARNAUS, R. La formación del profesorado: Un encuentro comprometido con la complejidad educativa. In: RASCO, J. F.; RUIZ, J. B.; GÓMEZ, A. P. (Ed.) Desarrollo profesional del docente: Política, investigación y prática. Madrid: Akal, 1999. p. 599-635.

AZEVEDO, P. D.; PASSOS, C. L. B. Professoras da Educação Infantil discutindo a Educação Matemática na Infância: o processo de constituição de um grupo. In: BETTA, M. Q. C. P. dos S.; BAIRRAL, M. A. (Org.) Matemática e Educação Infantil: Investigações e possibilidades de práticas pedagógicas. Petrópolis/RJ: Vozes, 2012. v. 1, p. 53-81.

CONTRERAS DOMINGO, J. La autonomia del profesorado. Madrid: Morata, 1997.

D'AMBROSIO, U. A educação matemática e o estado do mundo: desafios. In: CONGRESO IBEROAMERICANO DE EDUCACIÓN MATEMÁTICA-CIBEM, 7, 2013, Montevideo (Uruguay). Montevideo (Uruguay): Palestra Magna.

D'AMBROSIO, U.; D'AMBROSIO, B. The role of ethnomathematics in curricular leadership in mathematics education. Journal of Mathematics Education at Teachers College, New York/NY, v.4, n. 1, p.10-16, (Primavera - Verão). 2013.

DEWEY, J. Cómo pensamos: nueva exposición de la relación entre pensamiento reflexivo y proceso educativo. Tradução de Marco Aurelio Galmarini. Barcelona: Paidós, 1989.

ELLIOT, J. Actuación profesional y formación del profesorado. Cuadernos de Pedagogía, Madrid, n.191, p. 76-80, 1991.

FREIRE, P. Pedagogia da autonomia - saberes necessários à prática educativa. 31. ed. Rio de Janeiro: Paz e Terra, 2005.

GUTIERREZ, R. Mathematics teachers using creative insubordination to advocate for student understanding and robust mathematical identities. In: MARTINEZ, M.; CASTRO SUPERFINE, A. (Ed.). Proceedings of the 35th annual meeting of the North American Chapter of the Inter-national Group for the Psychology of Mathematics Education. $35^{\text {th }}$ Chicago, IL: Proceedings... Chicago, IL: University of Illinois at Chicago, 2013. p. 1248-1251.

HAYNES, E.; LICATA, J. W. Creative insubordination of school principals and the legitimacy of the justifiable. Journal of Educational Administration, Bingley, England. v. 33, n. 4, p. 21-35 ,1995. http://dx.doi.org/10.1108/09578239510147342

HUTCHINSON, S. A. Responsible subversion: A study of rule-bending among nurses. Scholarly Inquiry for Nursing Practice An International Journal, Nova York, v. 4, n. 1, p. 3-17, Primavera. 1990.

IMBERNÓN, F. La formación e la profesionalización en la función pedagógical. In: IMBERNÓN, F.; FERRERES V. S. (Org.) Formación y actualización para la función pedagógica. Madrid: Síntesis, 1999. p. 13-24.

LOPES, C. E. A produção de saberes de uma professora de matemática em um projeto de educação estatística. In: CONGRESO IBEROAMERICANO DE EDUCACIÓN MATEMÁTICA- CIBEM, 7., 2013, Montevideo (Uruguay). Actas... Montevideo (Uruguay): Palestra Magna, 2013. p. 4859-4866. 
LOPES, C. E. O conhecimento profissional de professores da Educação Infantil e suas relações com a Estatística e a Probabilidade. 2003. 281f. Tese (Doutorado em Educação) - Faculdade de Educação, Universidade Estadual de Campinas, Campinas/SP, 2003.

MCPHERSON, R. B.; CROWSON, R. L. The principal as mini-superintendent under Chicago School Reform. 1993. Disponível em: <http://eric.ed.gov/?id=ED373432〉. Acesso em: 31/08/2014. Relatório de projetos de pesquisa.

MORRIS, V.C.; CROWSON, R.L.; HURWITZ JR., E.; PORTER-GEHRIE, C. The urban principal. Discretionary decision-making in a large educational organization. 1981. Disponível em: <http://eric.ed.gov/?id=ED207178>. Acesso em: 31/08/2014.

MORIN, E. Complexidade e transdisciplinaridade: a reforma da universidade e do ensino fundamental. Tradução de Edgard Carvalho. Natal: EDUFRN, 1999.

NACARATO, A. M.; GRANDO, R. C. Análise compartilhada de aulas: processo formativo na, da e sobre a docência. In: SEMINÁRIO INTERNACIONAL DE PESQUISA EM EDUCAÇÃO MATEMÁTICA, 4., 2009, Brasília, DF. Anais... Brasília, DF: UCB, 2009. p.1-17.

PASSOS, C. L. B. Narrativas de licenciandos de Matemática participantes em grupo de estudos. In: SILVA, V. L. G.; CUNHA, J. L. (Org.) Práticas de formação, memória e pesquisa (auto) biográfica. São Paulo: Cultura Acadêmica, 2010. p. 149-166.

POPE, R. Creativity: theory, history, practice. New York, NY: Routledge, 2005.

ROCHE, K. Moral and ethical dilemmas in Catholic school settings. In: BEGLEY, P. T. (Org.) Values and educational leadership. Albany, NY: SUNY Press, 1999. p. 255-272.

SCHÖN, D. A. Educando o profissional reflexivo: um novo design para o ensino e a aprendizagem. Porto Alegre: Artes Médicas, 2000.

SKOVSMOSE, O. Towards a Critical Mathematics Education Research Programme? In: SKOVSMOSE, O.; GREER, B. (Ed.). Opening the Cage: Critique and Politics of Mathematics Education.

Rotterdam/Netherlands: Sense Publisher, 2012. p. 343-368. (New directions in Mathematics and science education, v. 23).

Submetido em Abril de 2014. Aprovado em Julho de 2014. 